\title{
Por uma revisão estemática das versões medievais conhecidas em língua portuguesa dos diálogos de São Gregório ${ }^{1}$
}

\author{
Américo Venâncio Lopes Machado Filho*
}

RESUMO: A partir de colação das versões conhecidas em língua portuguesa dos Diálogos de São Gregório, motivada pelo aparecimento da edição do Manuscrito da livraria 522 (Machado Filho, inédito), testemunho do século XIV ou início do XV, cujos originais se encontram nos arquivos nacionais torre do tombo, em Lisboa, Portugal, apresenta-se uma nova proposta de classificação estemática para a tradição dessa obra de referência da cultura monástica beneditina medieval, em complemento à de Mattos e Silva, de 1971.

PALAVRAS-CHAVE: Edição crítica de textos; stemma codicum; Diálogos de São Gregório.

\section{Introdução}

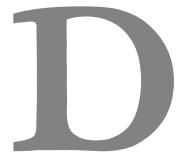

entre as obras de referência "qui ont été lus par tout le moyen âge" (Aigrain, 1933, p. 285) e que mereceram uma vasta tradição, quer direta " em latim ", quer indireta nas diversas línguas românicas que se firmavam no espectro centrífugo de Roma, encontram-se as obras de Gregório Magno (ઐ540-ヶ 6604), um dos mais destacados papas da Igreja Católica da Baixa Idade Média, de que foi considerado "Doutor Optimo" (cf. Azevedo, 1789, p. 120), em função da vasta atividade intelectual escrita e das inovações nos costumes religiosos que propôs.

1 O presente trabalho foi realizado com apoio do CNPq, uma entidade do Governo Brasileiro, voltada ao desenvolvimento científico e tecnológico.

* Universidade Federal da Bahia/Grupo de Pesquisa PROHPOR - americovenancio@gmail.com.

2 Tradução livre: "que foram lidas por toda a Idade Média". 
De sua rica produção destacou-se na Idade Média "a popularíssima obra Diálogos" (Silva Neto, 1950, p. v), que terá, indubitavelmente, experimentado uma exuberante fortuna de testemunhos em Portugal, mas cujo espólio, até o momento conhecido em língua portuguesa, se resume a quatro documentos, dentre eles três versões que mereceram edição crítica de Mattos e Silva (1971): a mais antiga " identificada pela autora pela letra (A) “, do século XIV (ms. Serafim da Silva Neto), cujos originais se encontram depositados na Biblioteca Central da Universidade de Brasília, no Brasil, códice alcobacense XXXVII/182, com datação provável entre os finais do século XIV e meados do XV (versão B) e o códice alcobacense XXXVI/181, datado de 1416 (versão C); e um testemunho que se encontrava esquecido, mas que foi descoberto na Torre do Tombo pelo Professor da Universidade da Califórnia, Arthur Askins, na década de 90, recentemente editado por Machado Filho (inédito), cotado como o Manuscrito da Livraria 522, cuja datação proposta por seu editor " baseada em dados paleográficos e lingüísticos " circunscreve sua produção ao período compreendido entre os finais do século XIV e os inícios do $\mathrm{XV}$, que doravante se identifica como a versão $\mathrm{D}$.

O imenso valor documental do pensamento religioso e da composição social italiana do século VI, refletidos no conjunto dos Diálogos de São Gregório, revelam-se como inestimável fonte para a história, considerando-se seu espectro de utilização mais difusa e geral, e como registro preciosíssimo para estudos lingüísticos " especificamente ", em função das possibilidades de variação grafemática, lexical, morfológica ou sintática que possa desvendar o confronto entre suas versões.

\section{O estado da questão}

Como antes referido, coube a Mattos e Silva (1971) o trabalho de edição crítica das três versões identificadas como $A, B$ e $C$ e o estabelecimento da primeira proposta de filiação genética para essa obra em língua portuguesa.

Para a realização de sua análise, diz a autora ter se comportado "heterodoxamente", no sentido de partir de aproximações sucessivas: os erros nìtidamente de cópia, às divergências sistemáticas e porventura menos significativas que apenas poderiam ser variantes resultado de atualização da linguagem ou de hábitos lingüísticos distintos entre os copistas e seus modelos, até chegar ao exame minucioso dos títulos, à estruturação da obra e às divergências mais significativas entre as três versões, selecionadas como informativas e que, sem dúvida, poderiam sugerir pistas seguras para a classificação dos códices (1971, v. I , p. 34). 
Não obstante alegue heterogeneidade no método empregado " talvez em função de, além de considerar a história individual de cada uma das versões, que reconstitui detalhadamente, observar todas as variantes de caráter fonético-fonológico e morfossintático, assim como "as variações possíveis resultantes de tradução diversa do latim ou de outro latim tido como modelo [...] todos os erros, saltos e repetições que ocorrem nas três versões" (id., p. 33) ", culmina numa proposição estemática bastante adequada, no sentido em que não a apresenta como "definitiva nem peremptória", mesmo porque "o aparecimento de outras versões, ou outro enfoque dado ao estudo das variantes, podem pôr abaixo todo êsse alicerce porventura frágill", como afirma (id., p. 41).

Aliás, para Sirat (1992, p. 166),

l'édition critique est un mythe parce qu'elle veut être parfaite ou totale, revenir au texte authentique ou donner un tableau complet de tradition manuscrite. Dans le deux cas, nous savons maintenant que cela est impossible. [...] Nous sommes plus modestes que nos prédécesseurs et savons qu'une oeuvre scientifique n'est jamais définitive, que l'éditeur d'un texte ne peut pas réunir en sa personne toutes les compétences présentes et futures.

Chega, então, a autora às seguintes hipóteses de filiação para as três versões estudadas, abaixo reproduzidas nas figuras 1 e 2 :

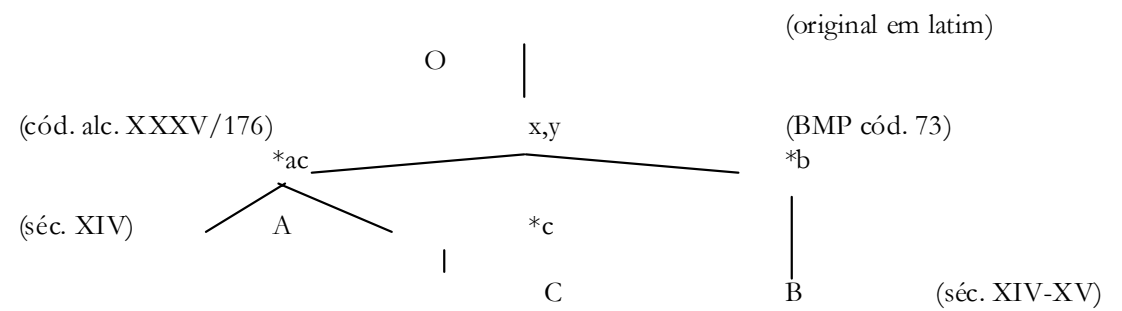

Figura 1: Hipótese 1, conforme Mattos e Silva (1971, p. 41)

Tradução livre: "a edição crítica é um mito porque quer ser perfeita ou total, chegar ao texto autêntico ou apresentar um quadro completo da tradição manuscrita. Nos dois casos nós sabemos hoje que isso é impossível. [...] Somos mais modestos que nossos predecessores e sabemos que uma obra científica nunca é definitiva, que o editor de um texto não pode jamais reunir em sua pessoa todas as competências presentes e futuras". 


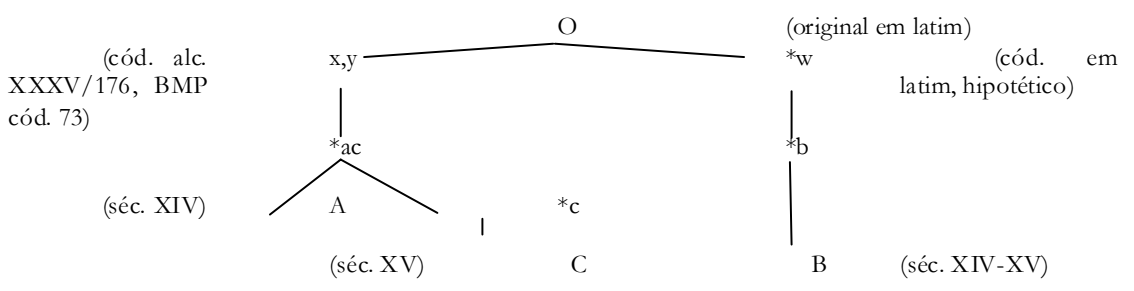

Figura 2: Hipótese 2, conforme Mattos e Silva (1971, p. 41)

Como se sabe, o stemma codicum, ou árvore genealógica, é a forma diagramática usualmente utilizada para se demonstrarem, em diversos níveis, prováveis relações genéticas existentes entre diversos testemunhos de uma mesma obra.

Os testemunhos são comumente representados pelo alfabeto latino maiúsculo, isto é, as letras A, B, C, D etc., os subarquétipos "las letras del alfabeto griego $a, b, g$.... (o sencillamente las minúsculas latinas $a, b, c \ldots.){ }^{\prime},{ }^{4} \mathrm{O}$ arquétipo a letra grega "w o simplemente uma x"5 (cf. Pérez Priego, 1997, p. 61), o O maiúsculo representa o original.

Interpretando-se a proposta de Mattos e Silva (1971), patente nas figuras 1 e 2 acima, verifica-se que existe uma proximidade maior entre $\mathrm{A}$ e $\mathrm{C}$, que, embora não sejam cópia um do outro, pressupõem a mesma relação subarquetípica e arquetípica em ambas as hipóteses.

A versão B, entretanto, apresenta um subarquétipo diferente das outras duas, tanto na primeira, como na segunda hipótese, e suscita, na outra possibilidade de filiação apresentada, a suposição de um arquétipo latino, que teria estado relacionado diretamente ao original gregoriano.

Note-se que o códice alcobacense XXXV/176 e o códice 73 da Biblioteca Municipal do Porto, apontados no estema como prováveis arquétipos em ambas as representações, foram, deveras, os testemunhos escritos em latim dos Diálogos de São Gregório do espólio medieval das bibliotecas portuguesas utilizados por Mattos e Silva (op. cit.) no confronto, para além do original latino.

\footnotetext{
4 Tradução livre: "as letras do alfabeto grego a, b, g... (ou simplesmente as minúsculas latinas $a, b, c . .$.$) ".$

5 Tradução livre: "w ou simplesmente um x".
} 


\section{3. "Trocando em miúdos"}

O primeiro problema que se poderia colocar na contramão do intuito da colação pretendida é de natureza metodológica, que, logo da partida, se poderia obstar em função de os critérios editoriais do Manuscrito da Livraria 522 não corresponderem precisamente aos adotados por Mattos e Silva (1971) em sua edição crítica.

Afinal, esse problema de falta de normalização de critérios de transcrição é, já, debate antigo e comumente se apresenta nos prolegômenos de quase todas as novas lições que vêm a lume, especialmente aquelas de textos medievais, quer galegos, quer portugueses. O certo é que não parece ser mero fruto do arroubo excessivo de alguns ou da extrema natura reacionária de outros, mas "na adequação dos critérios ao objetivo (ou objetivos) a que se destina a edição", isto é, "a depender dos interesses específicos de quem venha a utilizar essas edições, [...] critérios reguladores poderiam ser mais ou menos modernizadores ou, quiçá, conservadores demais" (Machado Filho, 2003, p. L).

Mas, reconsiderando-se a questão do método, se se compreender que, em crítica textual, nomeadamente no trabalho de colação, não "valdrán aquellas variantes indiferentes (equipolentes) que hacen perfecto sentido" (Pérez Priego, 1997, p. 57), e que, nesse particular, o formato de uma edição semidiplomática bem realizada corresponde satisfatoriamente ao de uma diplomática de mesmo grau de cuidado " conquanto, se deva admitir, seu confronto engendre algumas dificuldades, sobretudo no tocante à separação de palavras " 8 crê-se que a problemática relativa ao método possa ser suplanta$\mathrm{da}$, ao menos para um trabalho de natureza complementar como o presente, já que Mattos e Silva (op. cit.), ao circunscrever previamente os loci critici relevantes para a análise, facilita o levantamento das variantes significativas.

A primeira observação recai na questão de se o novo testemunho (Versão $D$ ) poderia ser cópia ou modelo para qualquer um dos outros, já que a análise de Mattos e Silva (id., p. 34) indica que “ $A, B$ e $C$ são cópias de manuscritos mais antigos", como, aliás, se constata na interpretação dos estemas acima apresentados.

Tradução livre: não "valem aquelas variantes indiferentes (equivalentes) que fazem perfeito sentido".

Sirat (1992, p. 164), com sua ânima crítica, diz que "il n'y a pas de 'bon' manuscrit mais des bonnes ou des manvaises leçons".

8 Na edição diplomática, com se sabe, não há intervenção do editor no sentido da operação de unir ou separar vocábulos que no original assim se apresentem. 
Se se considerar que é a existência de alguns saltos bordões fez com que, $\log$ a priori, a referida autora descartasse a possibilidade de $A$ "a mais antiga das versões" não ter servido de modelo para qualquer uma das outras, sobretudo o salto que identifica em 4.4.69-70, ${ }^{9}$ da sua edição crítica, vê-se que esse salto, assim como não ocorre nem em $B$, nem em $C$, também não se percebe em $D$, como se pode verificar no trecho sublinhado no fragmento abaixo:

a) $[\mathrm{D}-4-\mathrm{f} 82 \mathrm{r}-\mathrm{c} 2]^{10}$ Rogote pedro que me $\mid$ digas quẽ he oque todo esto obra . | ocorpo quese pode uéér que tira todos | estes penedos cõ suas maãos ou | aalma que auiuenta ocorpo. E çerta $\mid$ mente se tu tolheres do corpo aal $\mid$ ma quese nõ pode ueer todallas cousas | que amte ujas desapareçééo e nõ ueras | nẽ hũa cousa .

Entretanto, o salto, existente em 2.35 .23 de $A$ e que se confirma em $C$, repete-se com a mesma extensão em $D$, como se pode notar no trecho que se encontra tachado abaixo:

b) [D-2-f44r-c2] Epor tamto per | aquella tuz que eteon ollos to eorpo via recebeo outra luz demtro ẽ sua alma que | lhe alçou oentendimento tamto | mujto . que todallas outras cria | turas lhe pareçerõ muy pequenas | e muy baixas e por isso as uira | todas juntas sem afam e sem | ẽbargo nẽhuũ !

Do conjunto de seis saltos bordões indicados por Mattos e Silva (id., p. 34) que ocorrem em $C$, mas que não estão patentes em $A$, dois se reproduzem em $D$ :

c) (1.1.1) [D-1-f1v-c1] Ca dias em grego quer dizer em / | nosso timguagendous "lagos" en grego querdizerennosso rimanco palaura. E por es $\mid$ to este dialego . quer dizer. palaura $\mid$ de dous.

d) (1.1.23) [D-1-f2v-c1] . Ca algúús delles . de que $\mid$ me nenbro . despois que os deus apartou | do mundo sempre os teue linpos | e sááos . e sem uelhice da alma . | eno estado em queos chamou. Enũ $\mid$ ca lhes quis dar nem hũa hõrra $\mid$ no mundo . per que os tirasse do estacto fremoso e límpio pera que os chamara, que envelheeessen vivendo eon os homens do mundo das bulrras . e dos em | guanos . per que os que no mundo | uiuẽ soõe apassar .

9 Os números se referem respectivamente a: livro. capitulo. página, na edição de Mattos e Silva (1971). 
Os outros quatro saltos, entretanto, não ocorrem em $D$, o que permite inferir que $C$ não poderia ter sido seu modelo, embora não inviabilize, para já, a hipótese contrária.

Veja-se que todos os lapsos, identificados nos fragmentos abaixo, são de cópia e foram condicionados, isto é, são caracteristicamente homeoteleutos textuais, refletem saltos "do mesmo ao mesmo", palavras ou terminações idênticas, em distribuição e/ou posicionamento que probabilisticamente induziriam o copista ao erro. Como bem registra Beit-Arié (1992, p. 183),

Tant les scribes que les copistes étaient influencés par les mécanismes inconscients du travail de copie qui les faisaient inévitablement tomber dans des pièges et les amenaient à commetre certaines erreurs. Le processus physiologique, psychologique et mental de copie est complexe et n'a pas été suffisamment étudié et clarifié. ${ }^{11}$

e) $(1.5 .30)^{12}[\mathrm{D}-1$-f6r-c2] E andã $\mid$ do assy cercando todoo orto / A | chou acarreira per hu oladram | soya auỹr / e andando catando | mais pello orto. se acharia a | lgũa mal feitorya mayor que | aquela que achara.

f) (3.15.62) [D-3-f56r-c1] pera nõ | ẽ soberueçesem per morte demuy podero | ssos e muy fortes seus contrairos . quando | huũs poucos seus uezinhos que erã seus | contrairos cõ pequeno poder e pequena | força que aujã tamtas batalhas dauã e | ẽ tamta presa os tiinhã .

g) (4.32.22) [D-4-f99r-c2] E tamto que | os preguntarõ em que ora morrera . | acharom que morrera quamdo fora | chamado per aquelle homẽ que | morrera no moesteiro .

h) (4.38.4) [D-4-f106r-c1/2] Aqueste dõ pasco | al quamdo foy acomtenda antre | simaco e lourecço qual delles seria papa emlegeo loureço por papa .

10 A letra inicial corresponde à versão, o primeiro número ao livro, seguido do número do fólio e da coluna no manuscrito, já que a lição é inédita.

11 Tradução livre: "Tanto os escribas quanto os copistas eram influenciados pelos mecanismos inconscientes do trabalho de cópia que os fazia, inevitavelmente, cair em armadilhas e os conduzia a cometer certos erros. O processo fisiológico, psicológico e mental de cópia é complexo e não foi suficientemente estudado e esclarecido.

12 Em Mattos e Silva (1971, v. 1, p. 34) consta 1.5.31-32. 
434 MACHADO FILHO, Américo V. L. Por uma revisão estemática das versões medievais...

Ademais, além de $C$ e $D$ comungarem o salto bordão no fragmento ii), acima, sinalizam com as mesmas variantes morfossintáticas na seqüência do salto: "das bulrras e dos enguanos", face a $A$, "nas bulras e nos enganos".

A relação estabelecida pelos erros de salto se poderia transcrever, então, da seguinte forma: $D=\{\varnothing, \mathrm{b}, \mathrm{c}, \mathrm{d}\} ; \mathrm{C}=\{\varnothing, \mathrm{b}, \mathrm{c}, \mathrm{d}, \mathrm{f}, \mathrm{g}, \mathrm{h}\} ; \mathrm{A}=\{\mathrm{a}, \mathrm{b}\}$, que poderia, provisoriamente, sugerir uma filiação genética de $C$ em relação a $D$, porém não o contrário, o que apenas um exame mais detido de variantes pode confirmar ou contradizer.

Realizado o confronto dos títulos dos capítulos das versões $C$ e $D$, revelou-se o Quadro 1 seguinte, para que foram, obviamente, considerados apenas os capítulos passíveis de comparação, já que os testemunhos são fragmentários: ${ }^{13}$

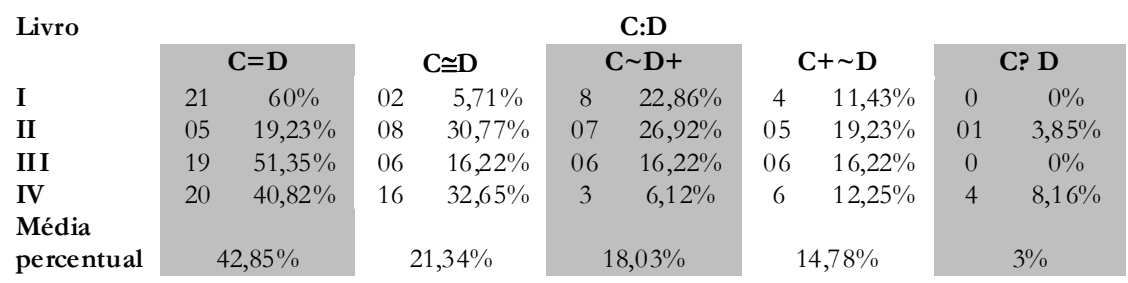

Quadro 1: Confronto dos títulos dos capítulos patentes em $C$ e em $D$.

Se se detiver aos casos em que $C$ difere completamente de $D$, isto é, a apenas $3 \%$ das ocorrências, verifica-se que os títulos discordantes no Livro II, existentes em $C$ ("O primeiro capítulo fala de Sam Beento") e em $D$ ("Como sam beento renũciou omũdo e opri | meiro milagre que deus por el fez”), não correspondem nem ao original latino, nem ao Códice Alcobacence XXXV/176, nem ao Códice 73, da Biblioteca Pública Municipal do Porto (BPMP).

Todavia, os títulos dos capítulos IV e V “ correspondentes ao testemunho $D$ “ que não aparecem no quarto livro de $C$, encontram correlato tanto no original latino como no Códice 73 da BPMP, como se pode constatar, respectivamente, na reprodução abaixo:

13 Legenda proposta: C:D ( $C$ em oposição a $D) ; \mathrm{C}=\mathrm{D}$ (se há variação, esta é meramente gráfica); $\mathrm{C} \cong \mathrm{D}$ (variação meramente lexical e/ou morfossintática); $\mathrm{C} \sim \mathrm{D}+(C$ em variação a $D$, no sentido de que este apresenta redação mais completa ou clara); $\mathrm{C}+\sim \mathrm{D}+(C \mathrm{em}$ variação a $D$, no sentido de que aquele apresenta redação mais completa ou clara); $C$ “"D ( $C$ difere de $D)$. 


\begin{tabular}{|c|c|c|}
\hline \begin{tabular}{l}
\multicolumn{3}{c}{ Original $^{14}$} \\
De quaestione animae \\
invisibiliter exeuntis an sit quae \\
videri non possit
\end{tabular} & $\begin{array}{l}\text { Cód. } 73 \text { BPMP } \\
\text { De questione anime invisibiliter } \\
\text { exeuntis an sit que videri non } \\
\text { possit }\end{array}$ & $\begin{array}{l}\text { Testemunho } \boldsymbol{D} \\
\text { da quastom da alma que sae em | } \\
\text { visiuil }\end{array}$ \\
\hline $\begin{array}{l}\text { Quod vita animae manentis in } \\
\text { corpore sicut depraehenditur ex } \\
\text { motu membrorum sic vita } \\
\text { animae post corpus in sanctis } \\
\text { pensanda est ex virtute } \\
\text { miraculorom }\end{array}$ & $\begin{array}{l}\text { Quid vita anime morientis in } \\
\text { corpore sicut deprehenditur ex } \\
\text { motu membrorum sic una } \\
\text { animae post corpus in sanctis } \\
\text { pensanda est ex virtute } \\
\text { miraculorom }\end{array}$ & $\begin{array}{l}\text { que aalma | he no corpo comose } \\
\text { mostra pollo mouy | mẽto dos } \\
\text { nenbros }\end{array}$ \\
\hline
\end{tabular}

As duas outras situações, em que não há correspondência entre as duas versões, referem-se às rubricas dos capítulos XLVI "De como hũũ santo homen quando viu morte ficou espantado" e LXVI "Da alma de Justo monge", do quarto livro de $C$.

A primeira encontra eco em todos os testemunhos em português e em latim, inclusive no original, à exceção de $B$ (e, obviamente, de $D$ ). A segunda, no entanto, embora apareça na versão $A$, no Cód. alc. XXXV/176 e no Cód. 73, enfrenta variante em $B$ e não se manifesta no original latino.

Isso parece indicar que $C$ não poderia, incondicionalmente, ser cópia direta de $D$, senão pela via da contaminação com outro modelo. Mattos e Silva (id., p. 39) chega a cogitar a possibilidade de $C$ " em função de ter sua origem na Livraria de Alcobaça "ter sido "confrontado com o latim do cód. alc. XXXV/176", por seu escriba e tradutor, Frei Estevão Anes, cuja apresentação autoral se registra em letra tardia na folha de rosto do códice.

Sem embargo, pelo que se pôde até o momento depreender, a vinculação entre $D$ e $C$ é evidente, se se considerar, sobretudo, que

ce que les copiste médiévaux réalisaient en copiant les textes était indubitablement ce qui est connu dans les théories de critique textuelle modernes comme un phénomène de décontruction puis reconstruction du texte (Beit-Arié, 1992, p. 195). ${ }^{15}$

O grau de variação desse período era, como se sabe, inconcebível para os padrões contemporâneos. Prova disso é a conhecida variação entre as duas únicas cópias existentes do Testamento de Afonso II (1214) (cf. Costa, 1979) ou, mais especificamente, a variação interna que ocorre entre os títulos do pró-

14 Cf. Mattos e Silva (id., p. 67) de onde se extraíram os exemplos do Original latino e do Cód. 73 BPMP.

15 Tradução livre: "o que os copistas medievais realizavam ao copiar textos era indubitavelmente o que é conhecido nas teorias da crítica textual moderna como um fenômeno de desconstrução e reconstrução do texto". 
prio Ms. da Liv. 522 e as anotações que se encontram à margem dos fólios em letra gótica cursiva " que serviriam para guiar o iluminador em seu trabalho e deveriam ser posteriormente raspadas “, mas que, talvez por descuido geral na finalização do projeto, não o foram. Diversos são os erros de leitura do rubricador com conseqüências para o estabelecimento pleno do que originalmente se havia programado para os títulos (cf. Machado Filho, inédito). Se se confrontassem sistematicamente essas anotações marginais e o efetivo registro das rubricas nesse manuscrito, ter-se-ia um quadro bastante revelador e interessante exemplo dos percalços que se impunham ao processo de produção codicológica medieval.

Mas retornando à avaliação estemática aqui proposta, Mattos e Silva (op. cit.), na tentativa de melhor demonstrar a aproximação de $A$ a $C$, concebe quatro tipos de situações específicas para análise dos lugares variantes entre esses dois testemunhos: o primeiro indicaria casos em que "a lição de $C$ 'corrigiria' a lição incompleta, errônea ou supérflua de $A$ " (id., p. 38); o segundo, em que $C$ parece tentar, por vezes insatisfatoriamente, adaptar ou atualizar trechos do texto; o terceiro, em que " $A$ e $C$ são coincidentes numa omissão que muito importa ao contexto" (ib.), mas que não ocorre no texto em latim; finalmente, o quarto, "em que $C$ procura corrigir uma lição incompreensível no seu modêlo que poderia ser igual à de $A$ " (ib.). A avaliação detida desses lugares variantes, elencados por Mattos e Silva (id.: 44-47), comparados a $D$, revelou o Quadro 2 seguinte, que se representa pelo sistema de identificação numeral proposto por essa autora:

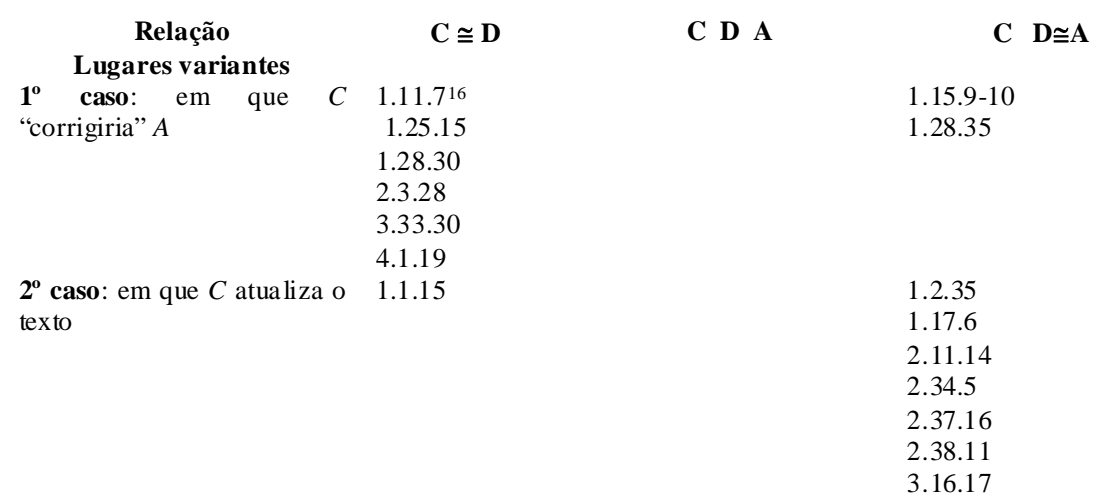

16 Em Mattos e Silva (1971, v. I, p. 44) consta, equivocadamente, 1.1.17. O lugar 2.2.13 não foi considerado em função de haver discrepância entre o confronto apresentado pela autora e o aparato crítico. 


\begin{tabular}{|c|c|}
\hline $\begin{array}{l}3^{\circ} \text { Caso: em que } C \text { e } A \\
\text { omitem } \\
\text { relevante }\end{array}$ & 2.4.16 \\
\hline $4^{\circ}$ caso: em que $C$ busca & 2.4 .7 \\
\hline corrigir trecho & 3.20 .17 \\
\hline incompreensível no modelo & 4.14 .3 \\
\hline
\end{tabular}

Quadro 2: Lugares variantes de $A$ em relação a $C$, em confronto com $D$.

O comportamento de $D$ em relação a $C$ é bastante curioso nos dois primeiros casos acima demonstrados: a cada falta de correspondência entre esses dois testemunhos, uma correlação entre aquele e $A$ se estabelece.

Os terceiro e quarto casos, entretanto, são mais esclarecedores. Vejamse as ocorrências:

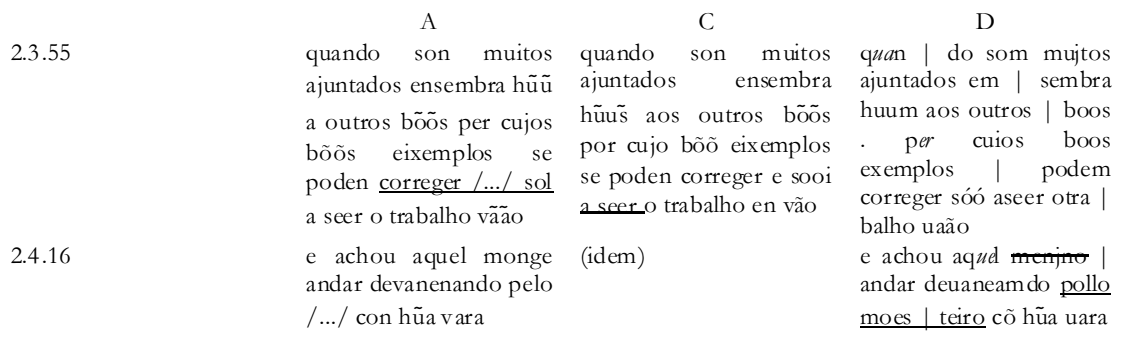

Em 2.3.55 todos os três testemunhos comungam de uma mesma omissão que não se encontra patente no Cód. Alc. XXXV/176, latino. Seria um erro conjuntivo, que se encontra "en dos o más manuscritos y que no han podido ser cometidos por sus amanuenses independientemente", transformando-se em "una garantía de la conexion existente entre las copias" (cf. Ruiz, 1985, p. 99).

Paradoxalmente, em 2.4.16, além da oposição menjno (D) : monge (A/C), a omissão não ocorre, podendo constituir-se em variante separativa ou disjuntiva, isto é, a "presencia en un ejemplary su ausencia en otros indica la independencia de dicho manuscrito respecto de los otros" (id.: ib) com vistas ao classificatio pretendido. Note-se, porém, que o trecho "aquel menjno" ocorre no manuscrito na mesma coluna em posição final da margem direita, cinco linhas abaixo, o que poderia indicar um "salto de ojos" (cf. Ruiz, 1985, p. 90). 
A

(2.4.7) vio San Beento que hũu meñiho negro o tirava pela ourela da vestidura fora da eigreja aquel monge que non podia estar na oraçom.
C

: pela orelha e pela vistidura o levava fora da egleja

(4.14.3) Muitas vegadas aven que por conforto da alma que se ha de partir do corpo, sol aparecer o outor e agalardoador : o outro ben e o galardoar da da vida perduravil.

\section{$\mathrm{D}$}

[f27r-c2] ujo sam | béénto que hũu menino negro | irau polla orelha nõ podia star na oraçõ.

[f62r-c1] cade | ues tu mááo | see sempre selhe podera achar algũa | cousa dequeo acuse quamdo esteuer | amte afaçe do juiz aquese nẽ hũa cou | sa escomde.

[f87v-c1] mujtas uezes auẽ que por | comforto daalma quesea departir do cor I po sooe apereçer ho outro e ogallardoar | dauida perdurauil . saber pedro queo spirito

Entrementes, observando-se detidamente os loci critici apontados no quarto caso, em que, para Mattos e Silva (op. cit.), C busca "corrigir trecho incompreensível no modelo", se tem razão a autora ao propor essa situação de $C$ face a seu modelo, poder-se-ia conjecturar, pelas lecciones acima apontadas, que não seria tão improvável que $D$ tivesse sido esse modelo, talvez o principal, porém não o único, já que, como antes se advertiu, pode ser $C$ o resultado de uma contaminação.

Ademais, a versão $D$ parece, estruturalmente, ser " se considerada a composição dos capítulos “ a mais próxima do original latino. É também o único testemunho que apresenta antes de cada um dos livros as respectivas "tavoas" ou sumário.

Considerando, ainda, a questão da datação, o testemunho $C$ é um documento do primeiro quartel do século XV, mais precisamente de 1416, como antes se viu, dado cronológico que, se confirmado, não obsta a sua filiação a $D$, já que o estudo preliminar realizado para uma proposta de datação, con- 
cluiu por se tratar de "um texto produzido entre a última metade do século XIV e a primeira do século XV" (cf. Machado Filho, inédito, p. xxxv).

\section{Por Uma Nova Configuração Estemática, Embora Não-conclusiva}

Com base nas avaliações empreendidas, sobretudo, pela consideração dos erros conjuntivos e separativos antes apontados, poder-se-ia propor, porém provisoriamente, as seguintes hipóteses de filiação para a tradição dos Diálogos de São Gregório em língua portuguesa, sobre o estema apresentado por Mattos e Silva, em 1971:

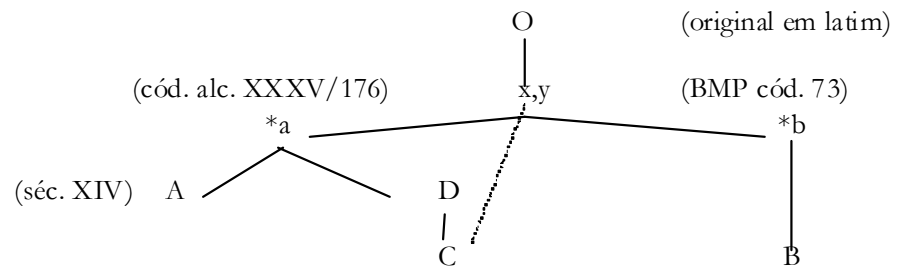

(séc. XIV-XV)

Figura 3: Nova proposta hipotética 1 de filiação dos mss. conhecidos dos Diálogos de São Gregório

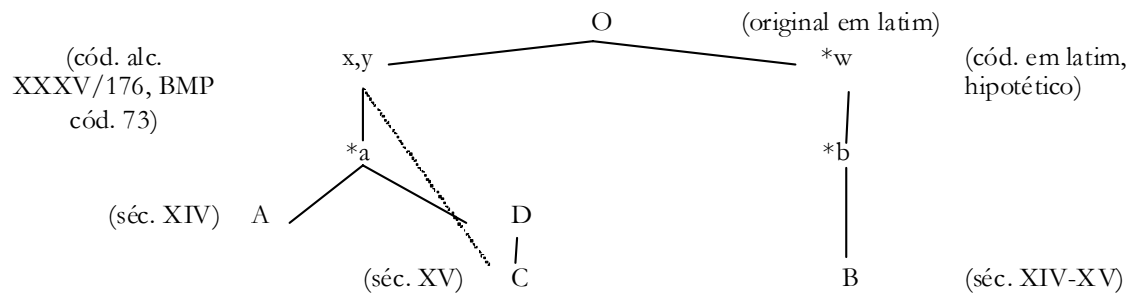

Figura 4: Nova proposta hipotética 2 de filiação dos mss. conhecidos dos Diálogos de São Gregório

Se se considerar que "los testimonios no son meros portadores de errores y variantes, sino que poseen una específica fisiononomía cultural"17 (Pérez Priego, 1997, p. 36) e que por mais que conclame a crítica textual de ser capaz de recuperar

17 Tradução livre: os testemunhos não são meros portadores de erros e variantes, senão que possuem uma fisionomia cultural específica." 
a história genética de um texto, qualquer estudioso de bom senso há de compreender que o passado (re)construído pela inteligência humana é meramente "uma aproximação" da realidade que se perdeu, como bem diria Mattos e Silva (no prelo).

Se não é a crítica textual apenas "um mito", como apregoa Sirat (op. cit.), seu exercício serve ao menos como uma tentativa de recuperação parcial do que poderia ter sido a história de um texto e o passado que o precedeu.

Nesse sentido, a proposta que aqui se apresenta é tão provisória quanto aquela apresentada por Mattos e Silva em 1971. Talvez novos testemunhos, talvez novas interpretações...

\section{Bibliografia}

AIGRAIN, R. (dir.) (1933) Ecclesia: encyclopédie populaire des connaissances religieuses. Paris: Librairie Bloud et Gay.

AZEVEDO, J. de (1789) Chronologia dos summos pontifices romannos, extrahida dos melhores authores da historia ecclesiastica. Lisboa: Regia Officina Typografica.

BEIT-ARIÉ, M. (1992) Transmission de textes par scribes et copistes. Interférences inconsientes et critiques. In: HAMESSE, J. (ed.) Les problèmes posés par l'édition critique des textes anciens et médiévaux. Louvain-la-Neuve: Université Catholique de Louvain. p.173-196.

CARDEIRA, E. (2005) Entre o português antigo e o português clássico. Lisboa: IN-CM.

CASTRO, I.; RAMOS, M. A. (1986) Estratégias e táctica da transcrição. In: COLLOQUE CRITIQUE TEXTUELle PORTUGAISE, 1981, Paris. Actes... Paris: Fundação Calouste Gulbenkian. p. 99-122.

COSTA, Padre A. de J. da (1979) Os Mais antigos documentos escritos em português. Revista Portuguesa de História, XVII, p. 263-340.

ILLESCAS, G. de (1578) Historia pontifical, y catholica enla qual se contienen las vdas y hechos notables, de todos los summos Pontifices Romanos. con el discurso de la Predicacion Apostolica. y el estado de la yglesia christiana Militante dende que CHRISTO nuestro sen)or nascio, hasta nuestros tiempos. Burgos: Martin de Victoria, Impressor de la Real Catholica Magestad.

LAUFER, R. (1972) Introduction à la textologie: vérification, établissement, édition des textes. Paris: Larousse.

MASS, P. (1958) Critica del testo. Trad. Nello Martinelli. 2. ed. Firenze: Felice Le Monnier.

MACHADO FILHO, A. V. L. (inédito). Diálogos de São Gregório (Manuscrito da Livraria 522): edição diplomática. (digitado).

MATTOS E SILVA, R. Vi. (1971) A mais antiga versão portuguesa dos "Quatro livros dos diálogos de São Gregório”. Edição crítica com Introdução e Índice geral das palavras lexicais. São Paulo. Tese (Doutoramento). Faculdade de Filosofia, Letras e Ciências Humanas da Universidade de São Paulo.

--___ (1993) Diálogos de São Gregório. In: LANCIANI, G.; TAVANI, G. (orgs.). Dicionário da literatura medieval galega e portuguesa. Lisboa: Caminho. p. 215-216. 
(no prelo) O português arcaico: uma aproximação. [a sair pela IN-CM].

PÉREZ PRIEGO, M. Á. (1997) La edición de textos. Madrid: Editorial Síntesis.

RUIZ, E. (1985) Crítica textual. Edición de textos. In: DIÉZ BORQUE, J. M. (coord.). Métodos de estudio de la obra literaria. Madrid: Taurus. p. 67-120.

SIRAT, C. (1992) Les éditions critiques: un myhthe? In: HAMESSE, J. (éd.) Les problèmes posés par l'édition critique des textes anciens et médiévaux. Louvain-la-Neuve: Université Catholique de Louvain. p. 159-171.

ABSTRACT: The main purpose of this paper is to present a new stemma, or "family tree," of the surviving Portuguese written witnesses of the tradition of the dialogues of St. Gregory based on Mattos e Silva 1971's previous work and motivated by the edition of the manuscrito da livraria 522 (Machado Filho, unpublished), a XIVth. Or XVth. century version, recently discovery at the Torre do Tombo, in Lisbon, Portugal.

KEYWORDS: Textual criticism; stemma codicum; Gregory the Great's Dialogues. 